\title{
IMPORTANCE OF INCORPORATION OF GEOSPATIAL TECHNOLOGY APPLICATIONS IN WATER RESOURCES AT GRADUATE AND POST-GRADUATE COURSES OF CIVIL ENGINEERING
}

\author{
Vaibhav Garg $^{1 *}$, Bhaskar R. Nikam ${ }^{1}$, Praveen K. Thakur ${ }^{1}$, S.P. Aggarwal ${ }^{1}$, Arpit Chouksey ${ }^{1}$ and Pankaj R. Dhote ${ }^{1}$
}

${ }^{1}$ Water Resources Department, Indian Institute of Remote Sensing, Kalidas Road, Dehradun - 248 001, Uttarakhand (vaibhav, bhaskarnikam, praveen, spa, arpit, pdh)@iirs.gov.in

\author{
Commission V, WG V/7
}

KEY WORDS: water resources, geospatial technology, civil engineering, course curriculum

\begin{abstract}
:
Water is a very crucial element to sustain life on earth. The availability of water varies both spatially and temporally. India being a water stress country, the per capita availability of water is reducing with time. It is predicted that by 2050 around $54 \%$ of the country will be water scarce. The changing climate along with the ever-increasing population is putting additional stress on water availability. The science of water, its availability and distribution on earth and its atmosphere, is generally regarded as hydrology. The important aspects of hydrology and hydraulic or more broadly water resources are taught as the subject or optional subjects the branch of Civil Engineering at almost all engineering institutes/colleges at the undergraduate level. It is also one of the specializations for post-graduate level studies. It is, by now, well proven that the geospatial technology play crucial role in water resources assessment, planning and management. However, the young minds (graduate and post-graduate students) are just being trained for typical hydrology using traditional means and approaches. The advancement and potential of geospatial technology has drawn the attention of academician, and it has been started as a subject mostly at the post-graduate courses. Recently, some of the institutions have started courses on geoinformatics at the graduate level. However, the hydrology and geospatial technology are generally taught as two separate subjects under different course at different levels mostly under the broad subject of Civil Engineering. The present paper emphasis on needs and ways of updating Civil Engineering course curriculum by focusing on incorporation of applications of geospatial technology in hydrology as regular subject.
\end{abstract}

\section{INTRODUCTION}

The geospatial technology has huge potential in water resources studies. It has been applied in hydrology since the launch of Landsat series satellites way back in the 1970's. Geospatial technology can provide information on almost each and every aspect of hydrology either directly or indirectly (through modeling approach using remote sensing inputs) (Bhavsar, 1984; Bastiaanssen, 1998). The estimation of the most basic parameters of hydrology such as rainfall, water body, snow cover, soil moisture can be done easily through remote sensing (Thakur et al. 2017). The hydrological processes such as evapotranspiration, infiltration, interception, soil moisture and runoff (rainfall-runoff \& snowmelt runoff) can further be simulated through hydrological modeling incorporating remote sensing inputs. Further, at present the students are being taught the simple definition of the watershed, however, with the help of geospatial technology the students can delineate the watershed for any region by processing the digital elevation models (DEM) generated through remote sensing data. Further, remote sensing derived DEMs can be utilized in studying open channel hydraulics, river morphology, water distribution system, etc. In addition, it has an important role in understanding urban hydrology too such as storm drainage network analysis, storm drainage runoff estimation, water distribution, etc. Advanced hydrology topics such as glacial lake outburst flood, dam break analysis, etc. can be made easier for the students through remote sensing in the geospatial domain. Nowadays, the direct products on hydrological processes such as ET, soil moisture, precipitation, snow water equivalent, etc. generated through remote sensing approach are available in the public domain at no cost. Furthermore, various geospatial portals or web services such as India Water Resources Information System, Bhuvan, etc. provide useful information dealing with the basin boundary; location of the dam and their bathymetry; information of agricultural command area development, flood hazard mapping, basic inputs for hydrological modeling, etc. The students can utilise these products to carry out their respective projects of graduate and post-graduate level. Moreover, such datasets and services are very useful for calibration and validation of their study results. The integration of these two subject will improve the understanding of the students as they can visualize the results of the hydrological process in the geospatial domain such as simple analysis on the change in water body spread with time, change in snow cover over a period of time, flood inundation, flood modeling, hydrological processes modelling. Therefore, it can be concluded that there is an urgent need of updating and incorporating the use of geospatial technology in water resources subjects, for overall understanding and development of the student.

\section{PRESENT STATUS OF GEOSPATIAL TECHNOLOGY AS SUBJECT IN CIVIL ENGINEERING COURSES IN INDIA}

The All India Council for Technical Education (AICTE) Act (No. 52 of 1987) was constituted for the establishment of an AICTE with a views to proper planning and coordinated development of a technical education system throughout the country, promotion of qualitative improvements of such education in relation to planned quantitative growth, and regulation \& proper maintenance of norms \& standards in the technical education system and for the matters connected therewith. The purview of

* Corresponding author 
AICTE (the Council) covers programmes of technical education including training and research in Engineering, Technology, Architecture, Town Planning, Management, Pharmacy, Applied Arts and Crafts, Hotel Management and Catering Technology, etc. at different levels.

As per AICTE, there are different types of technical institutions such as private-aided, university managed (private), university managed, university managed (government), government aided, government, central university, deemed university (private) and deemed university (government) imparting education/training at different levels such as undergraduate (UG), post-graduate (PG) and diploma. As per the latest statistics, there are 6446 technical institutions (Figure 1a) other than MHRD governed (IITs, NITs, etc.) dealing with course of 'Engineering and Technology' in the academic year 2017-18 at all level spread across the country (www.facilities.aicte-india.org)

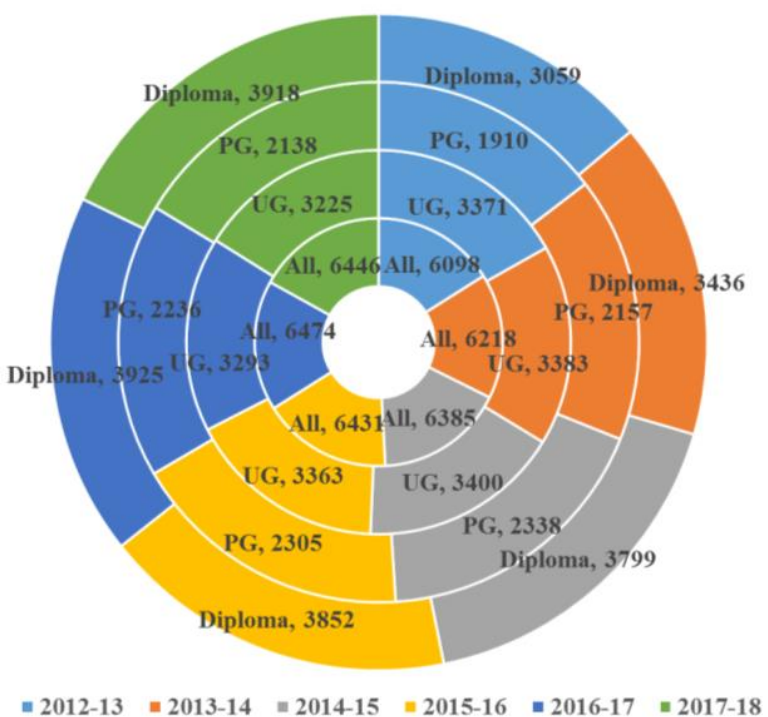

Figure 1a. AICTE Approved 'Engineering and Technology' Institutes for the Academic Years: 2012-13 to 2017-2018 (Data Source: AICTE)

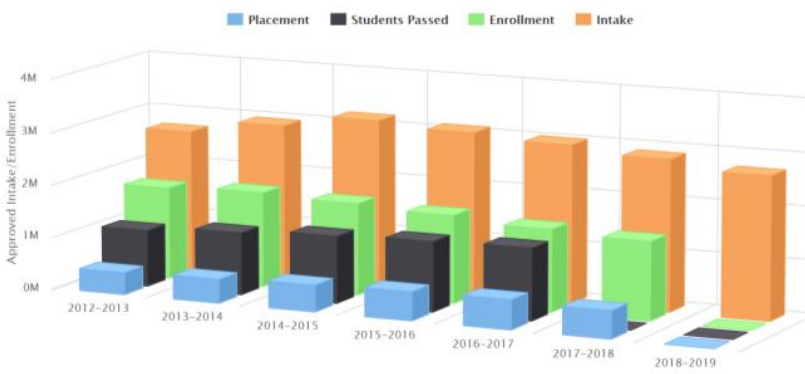

Figure 1b. Year Wise Statistics of approved Intake, actual enrollment, students passed and placement in the Engineering and Technology Institutes (Source: AICTE)

The maximum intake (approved) of these institutes is around $28,70,900$ (Figure 1b). In the year 2017-18, the total enrollment of the students was around 14,86,400 (www.facilities.aicteindia.org). It is to be noted that in almost all engineering and technology institution there is department of Civil Engineering. Figure 2 and Table 1 shows the state-wise institutes dealing with Civil Engineering at each level. It can be realized that every year the country is generating large number of Civil Engineering graduates. Still, the problem of water resources management in the country is in the unacceptable condition.

\begin{tabular}{|l|c|c|c|}
\hline State & UG & PG & Diploma \\
\hline Andaman \& Nicobar Islands & 1 & 0 & 1 \\
\hline Andhra Pradesh & 277 & 2 & 204 \\
\hline Arunachal Pradesh & 1 & 0 & 8 \\
\hline Assam & 12 & 3 & 17 \\
\hline Bihar & 31 & 0 & 57 \\
\hline Chandigarh & 2 & 1 & 1 \\
\hline Chhattisgarh & 47 & 1 & 50 \\
\hline Dadra and Nagar Haveli & 0 & 0 & 1 \\
\hline Daman and Diu & 0 & 0 & 2 \\
\hline Delhi & 4 & 0 & 4 \\
\hline Gao & 2 & 0 & 3 \\
\hline Gujarat & 119 & 8 & 116 \\
\hline Haryana & 113 & 28 & 146 \\
\hline Himachal Pradesh & 17 & 4 & 26 \\
\hline Jammu and Kashmir & 7 & 0 & 19 \\
\hline Jharkhand & 15 & 0 & 26 \\
\hline Karnataka & 177 & 3 & 263 \\
\hline Kerala & 137 & 1 & 43 \\
\hline Madhya Pradesh & 179 & 1 & 112 \\
\hline Maharashtra & 283 & 9 & 367 \\
\hline Manipur & 1 & 0 & 1 \\
\hline Meghalaya & 1 & 0 & 1 \\
\hline Mizoram & 0 & 0 & 1 \\
\hline Nagaland & 0 & 0 & 2 \\
\hline Odisha & 82 & 1 & 134 \\
\hline Puducherry & 8 & 0 & 3 \\
\hline Punjab & 83 & 9 & 121 \\
\hline Rajasthan & 105 & 0 & 150 \\
\hline Sikkim & 1 & 0 & 2 \\
\hline Tamil Nadu & 463 & 0 & 445 \\
\hline Telangana & 189 & 2 & 130 \\
\hline Tripura & 2 & 0 & 5 \\
\hline Uttara Pradesh & 240 & 13 & 364 \\
\hline Uttarakhand & 26 & 3 & 65 \\
\hline West Bengal & 66 & 4 & 116 \\
\hline & & & \\
\hline & 097 a & 0 \\
\hline
\end{tabular}

Table 1. Engineering \& Technology offering Under Graduate, Post Graduate and Diploma in Civil Engineering during Academic Year 2017-18 (Data Source: AICTE)

AICTE was set up as a national-level apex advisory body to conduct a survey on the facilities available for technical education and to promote development in the country in a coordinated and integrated manner with following goals:

- Statutory authority for planning, formulation, and maintenance of norms \& standards

- Quality assurance through accreditation

- Funding in priority areas, monitoring, and evaluation

- Maintaining parity of certification \& awards

- The management of technical education in the country

It ensures the quality of technical education through the accreditation and revision of the course curriculum regularly as per the demand. Recognizing the potential of geospatial technology in Civil Engineering, it has been partially introduced in the course curriculum. The technology has application in almost each specialized/core field of Civil Engineering such as construction \& building material survey; geotechnical monitoring; structural monitoring; surveying and water resources management (Thakur et al., 2008). Even after regular updating and modifications in the syllabus with respect to recent trends and requirement, the syllabus of Civil Engineering subjects needs further improvements by incorporating geospatial technology and its applications. 


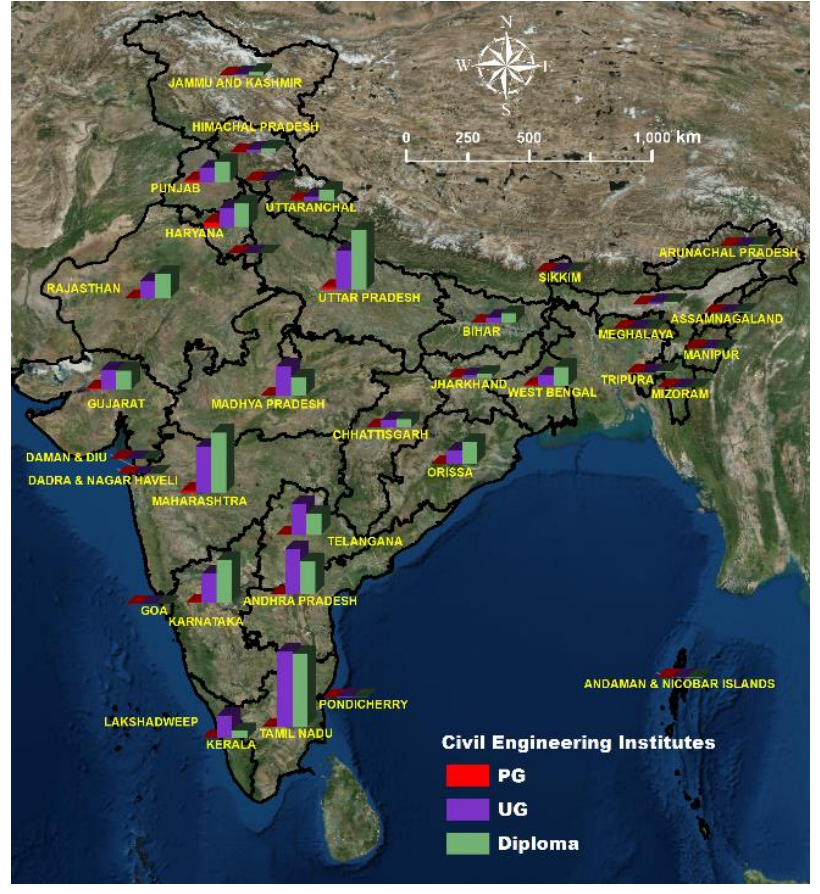

Figure 2. State wise distribution of Institutes offering UG, PG and Diploma in Civil Engineering (Data Source: AICTE)

Till date, the geospatial technology has been considered as a subject of Civil Engineering. At present, the geospatial technology has been restricted as a surveying tool at under graduate level and taught as a subject of surveying or geodesy in the fourth semester (AICTE, 2018) as shown in Figure 3. There is also a core course on "Hydrology \& Water

Resources Engineering" with focus on Water Quality Engineering; Surface Hydrology; Environmental Fluid Mechanics; and Water Resources Field Methods. In this course the students are generally exposed to the basics of hydrology and its assessment through traditional field instrumentation. The text books used by the students also do not have specific section on geospatial applications in different aspects of hydrology such as precipitation estimation, soil moisture assessment, rainfall runoff modelling, ground water modelling, etc.

However, geospatial technology has generally been taught as an elective subject in post-graduate courses of civil engineering. As per the Model Curriculum of Engineering \& Technology for PG Courses M. Tech (Civil Engineering) with specialization "Hydraulic Engineering", the objective of the four semester program are:

1. To learn the principles, processes and design of pressurized and free surface system.

2. To achieve competency in the pipe network design, analysis of channel networks, pressure rise in pipes due to sudden closure of valves, etc.

3. To assess the impact of climate change detection, Land use/Land cover changes on water availability

4. Efficient use of water in irrigation under varying climate change.

5. Impact of climate change on glaciers, consumptive use of surface and ground water, and optimum allocation of water.

6. Evaluation of various hydrologic processes including flow forecasting and the related practical applications.

To achieve these objectives the program is divided into four semesters. First semester, the students are exposed to Advanced
Hydrology, Advanced Fluid Mechanics and Research methodology \& IPR as core subjects with electives on Fluvial Hydraulics; Hydraulic Structures; System Engineering; Water Resources Systems Planning; Irrigation and Drainage. In the second semester, the student are taught following core subjects: Ground Water Engineering, Free Surface Flows; and a mini project, whereas, the electives are: Computational Methods in Fluid Mechanics, Theory and Applications of GIS; Environmental Hydraulics, Advanced Numerical Analysis. Third semester, there is choice for students to elect from the elective subjects such as Computer Methods in Hydraulics and Hydrology; Stochastic Hydrology; Business Analytics, Industrial safety; Operations Research; Cost Management of Engineering Projects; Composite Materials; Waste to Energy along with the Phase-I of the dissertation. In the final semester, students have to carry out their dissertation work.

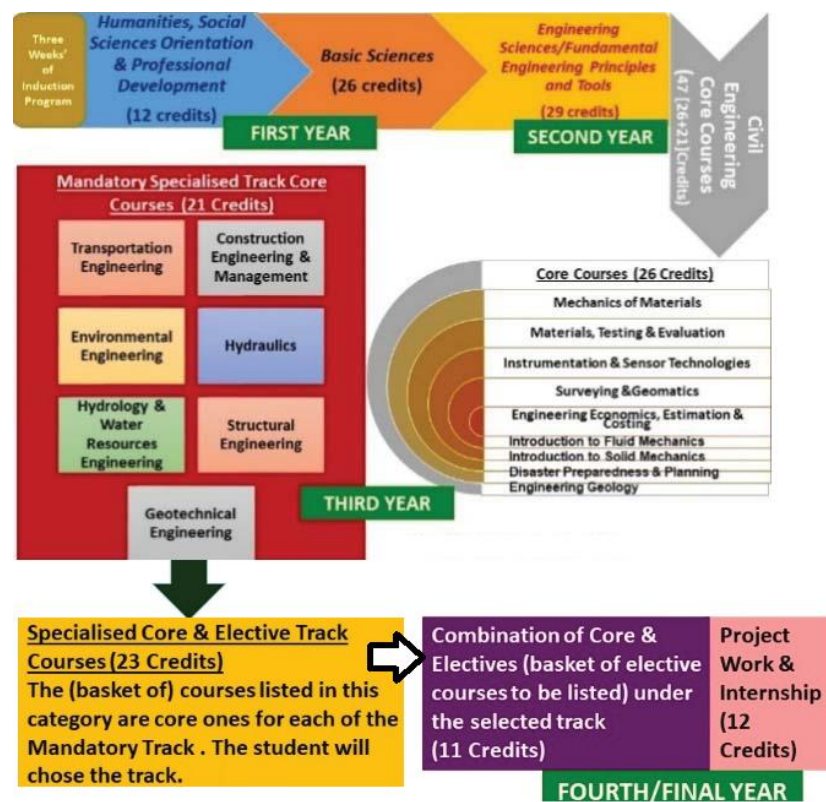

Figure 3. Structure of Undergraduate Civil Engineering Program (Data Source: AICTE)

The point to be taken from the above discussion is that, the geospatial technology has already proven its capabilities in addressing almost all the objectives of this program (Smith, 1997; Ritchie et al., 2003; Garg and Jothiprakash, 2012; Garg et al., 2012; Aggarwal et al., 2013; Garg et al., 2013; Aggarwal et al., 2014; Thakur et al., 2015; Garg et al., 2017a,b; Ghosh et al., 2017; Thakur et al., 2017a,b; Nikam et al., 2018; Nagesh Kumar and Reshmidevi, 2013).

Still, it has been taught as an Elective Course on "Theory and Applications of GIS in semester-II. The objective of this particular elective is: To teach the principles and applications of remote sensing, GPS and GIS in the context of water resources. At the end of the course, the students are expected to appreciate the importance of remote sensing and GIS in solving the spatial problems in water resources. Following is the syllabus/content of a typical elective offered in the institutes:

Unit I: Introduction, Geographical concepts and Terminology, Difference between Image Processing system and GIS, Utility of GIS.

Unit II: Various GIS packages and their salient features, Essentials components of GIS, Data acquisition through scanners and digitizers 
Unit III: Raster and Vector Data: Introduction, Descriptions: Raster and Vector data, Raster Versus Vector, Raster to Vector conversion, Remote Sensing Data in GIS Topology and Spatial Relationships, Data storage verification and editing

Unit IV: Data preprocessing, Georeferencing, Data compression and reduction techniques, Runlength encoding, Interpolation of data, Database Construction, GIS and the GPS, Data Output Database structure, Hierarchical data, Network systems, Relational database, Database management, Data manipulation and analysis

Unit V: Spatial and mathematical operations in GIS, Overlay, Query based, Measurement and statistical modelling, Buffers, Spatial Analysis, Statistical Reporting and Graphing

Unit VI: Programming languauges in GIS, Virtual GIS, Web GIS

Unit VII: Application of GIS to various natural resources mapping and monitoring and engineering problems

The focus of this elective course is mainly on GIS and very less emphasis is given to data processing with respect to water resources or hydrological processes.

Other courses taught during the graduation tenure of a Civil engineer with the objective of water resources management are:

\section{Advanced Hydrology}

Unit I: Introduction: Hydrologic system and hydrologic budget, fundamental laws of hydrology; atmospheric water vapor.

Unit II: Hydrologic Inputs: Precipitation and its forms, snowfall and rainfall; measurement techniques and space-time characteristics

Unit III: Hydrologic Abstractions: Infiltration, depression storage, evapotranspiration; measurement techniques, space time characteristics and their modelling.

Unit IV: Stream flow: Measurement techniques, space-time characteristics, rating curves System Approach: Unit Hydrograph IUH, GIUH

Unit V: Mathematical Modelling: Linear and Nonlinear models, Physically based models

Unit VI: Hydrological routing, Flood forecasting

Unit VII: Advanced Method of Frequency Analysis: Outliers, Time series analysis.

Unit VIII: Impact of climate change and Land use/Land cover on basin response

As mentioned above most of these aspects have already been addressed or studied through geospatial technology.

\section{Water Resources Systems Planning}

Unit I: Introduction: Water resources planning process, multi-objective planning.

Unit II: Evaluation of Water Plans: Basic concepts of engineering economics, welfare economics, economic comparison of alternatives.

Unit III: Water Plan Optimization: Plan formulation, objective functions and constraint, analytical optimization, numerical optimization, linear programming, dynamic programming, simulation, planning under uncertainty.
Unit IV: Deterministic River Basin Modeling: Stream flow modeling, estimation of reservoir storage requirements - dead storage, active storage for water supply/ irrigation / power generation, flood storage, optimal allocation.

Unit V: Conjunctive Use/Groundwater Management Models: LP based conjunctive use modeling, aquifer response models, link - simulation, embedded, matrix response based models, soft modeling.

Unit VI: Water Quality Management Models: Basic water quality modeling, objectives of management, control alternatives, optimal plans.

\section{Irrigation and Drainage}

Unit I: Introduction, objectives of irrigation, type of irrigation and suitability; selection of irrigation method.

Unit II: Irrigation requirement, water balance, soil water relationships, water storage zone, infiltration.

Unit III: Flow of moisture through root zone, soil physical and chemical properties, crop evaporative and drainage requirements, irrigation efficiency and uniformity.

Unit IV: Surface irrigation systems, types of surface systems, basin irrigation, border irrigation, furrow irrigation, field measurement techniques, flow measurement, flumes, weirs, irrigation events, advance, wetting, depletion and recession phases.

Unit V: Infiltration, infiltrometer, ponding methods, soil water, tensiometers, neutron probe, time domain reflectometer, evapotranspiration, crop coefficient, leaf area index, FAO guide lines on evapotranspiration estimation.

Unit VI: Fundamentals of surface irrigation hydraulics, continuity equation, momentum equation

Unit VII: Hydrodynamic model, zero inertia model, kinematic wave model

Unit VIII: Drainage principles, need for drainage, steady state equations, Hooghoudt, Kirkham, Dagan and Ernst equations.

Unit IX: Salt balance, water and salt balance of the root zone, salt equilibrium equation and leaching requirement, leaching efficiency.

\section{Computational Methods in Fluid Mechanics}

Unit I: Review of numerical techniques like method of characteristics, finite difference method.

Unit II: Finite element method.

Unit III: Modelling of steady state flow and hydraulic transients in pipes.

Unit IV: Modelling of non-uniform, transient spatially varied flows in open channels.

Unit V: Numerical solutions for Navier-Stokes, boundary layer and Reynolds equations.

Unit VI: Modelling of groundwater flow and contaminant transport in groundwater.

Most of the topics covered in these courses deal with spatiotemporal dynamics problem of water resources. The management of these problems in real world require spatio-temporal data. However, most of the traditional techniques taught to the Civil engineering graduates are based on the static (either spatially or temporally) observations. Remote sensing and associated technologies (which is termed as geo-spatial technology) provides opportunity to generate these important inputs at spatio- 
temporal level due to its ability of synoptic \& repeated coverage of area of interest.

To discuss with example the subject 'Water Resources Systems Planning' is taken up here. In water resources planning, the formulation of objective function (multi-objective) has to be bound by resources availability constraints. In this case availability of water acts as constraint for these objective functions. It is well known fact that availability of water in any natural or man-made reservoirs changes with time and space (Foteh et al., 2018). So, the constraint need to have both spatial and temporal descriptor of resources (water) availability. Quantifying this spatial and temporal change in water availability in itself is mammoth task in traditional techniques. However, multi-sensor, temporal remote sensing data analysis aided with ground observations can provide water resources assessment at any desired spatial $\left(\mathrm{m}^{2}\right.$ to $\left.\mathrm{km}^{2}\right)$ and temporal (day to annual) level. This inputs generated by integrating geo-spatial technology in traditional water resources planning process can solve water availability, distribution, utilization problems, considered as 'impossible to solve' in conventional approach. However, to this integration, the students need to have detailed knowledge of different platforms and sensors available, their data properties and processing techniques. As discussed previously the elective subjects of Remote Sensing and GIS technology do not cover this wide range of knowledge. Additional, geospatial technology has already proven its capabilities in most of the other aspects covered in above listed courses. If the application of geospatial technology, in each of the subject addressed through it, may be added along with the traditional methods, it will reduce one elective course. Further, it will help students to analysis, visualize the processes of hydrology much better. So, there is eminence need of incorporating geospatial technology in the syllabi of Civil Engineering.

\section{RECOMMENDATIONS OF THE STUDY}

It has been noticed that geospatial technology is taught as surveying tool under undergraduate courses of civil engineering. However, it has been taught as an elective subject in postgraduate level. Furthermore, under the elective course at post graduate level, it mainly focuses on GIS, the one aspect of the geospatial technology. Whereas, the geospatial technology as a whole has already proven its capabilities in almost all processes involved in hydrology, hydraulics and even urban hydrology. Therefore, following recommendation are made to improve the course curriculum of Civil Engineering with respect to water resources subjects.

1. An elective course on "Basics of geospatial technology" may be introduced in the semester III or IV for UG level students to enhance their knowledge on the aspects of geospatial technology and introduce the present capabilities of the same.

2. Along with teaching geospatial technology as a surveying tool in semester IV, the syllabus at UG level may be revised for semester V course on "Hydrology and Water Resources" by incorporating section in relevant units on application of geospatial technology. Subsequently, the textbooks may be revised with incorporation of geospatial technology applications in basic hydrology and water resources.

3. An introductory course on "Basics of geospatial technology" may also be added in the diploma courses of Civil Engineering. It will provide the diploma students exposure to this emerging technology and they will be able to take up field applications of the technology.

4. However, the post graduate courses of Civil Engineering are divided into various specializations based on the core subjects viz. Structural Engineering; Geotechnical Engineering; Transportation Engineering; Water Resources Engineering; Construction and Design; Environmental Engineering; Hydraulics, etc. The geospatial technology has varying applications in each of these specializations. At master's level introductory elective subject on geospatial technology mainly focused on GIS may not cater to the requirements/potential of all these disciplines to utilize geospatial technology. Hence, updation of syllabi of relevant subjects from all these disciplines should be taken up with aim of introducing the present and future applications of geospatial technology.

5. It has been noticed that the applications of geospatial technology are huge in the specialization of water resources engineering. So, it is recommended that the course structure of this discipline may be revised to accommodate the geospatial technology as a core subject. The syllabi of other core subjects should also be updated by incorporating the applications of geospatial technology in all the relevant units.

6. The application of geospatial technology in Civil Engineering could not get much attention due nonavailability of suitable resource persons. Therefore, there is an urgent need of training of the trainers (the faculty), which will enable the faculty to update and revise the course curriculum. There are other/different modes of receiving training in application of geospatial technology in water resources other than regular courses for professionals. There are dedicated institutes and departments funded by Indian Space Research Organisation to spread the potential of geospatial technology in water resources. Further details on such trainings can be found at Thakur et al., (2018).

7. Further to improve the present scenario of incorporation of geospatial technology in Civil Engineering at graduate level, the faculty must be encouraged to take up professional training or an e-content may be developed with the help of geoscientists/professionals working in these domains. This econtent may be hosted at a central server such as AICTE, UGC, MHRD to ensure the standardization of content and its uninterrupted availability to the user community (faculty and students).

8. It will help the nation to generate the large scale geoscientists, knowledgeable in water resources aspects with hands-on experience of applications of geospatial technology.

\section{REFERENCES}

Aggarwal, S.P., Garg, V., Gupta, P.K., Nikam, B.R., Thakur, P.K. and Roy P.S. 2013. Runoff potential assessment over Indian landmass: A macro-scale hydrological modeling approach. Current Science, 104(7), pp. 950-959.

Aggarwal, S.P., Thakur, P.K., Nikam, B.R. and Garg, V. 2014. Integrated approach for snowmelt run-off estimation using temperature index model, remote sensing and GIS. Current Science, 106 (3), pp. 397-407.

AICTE (All India Council for Technical Education) 2018. Model Curriculum for Undergraduate Degree Courses in Engineering \& Technology. Volume -1, All India Council for Technical Education, New Delhi, India (https://www.aicteindia.org/sites/default/files/Final\%20Draft__Vol.\%20I\%20\%20 AICTE\%20UG\%20\%20Curriculum.pdf)

Bastiaanssen, W.G.M. 1998. Remote sensing in water resources management: the state of the art. International Water Management Institute, Colombo, Srilanka. 
Bhavsar, P.D. 1984. Review of remote sensing applications in hydrology and water resources management in India. Advances in Space Research, 4(11), pp. 193-200, https://doi.org/10.1016/0273-1177(84)90411-3.

Foteh, R., Garg, V., Nikam, B.R., Khadatare, M.Y., Aggarwal, S.P., Senthil Kumar, A. 2018. Reservoir Sedimentation Assessment through Remote Sensing and Hydrological Modeling. Journal of the Indian Society of Remote Sensing, https://doi.org/10.1007/s12524-018-0843-6

Garg, V. and Jothiprakash, V. 2012. Sediment yield assessment of a large basin using PSIAC approach in GIS environment. Water Resources Management, 26(3), pp. 799-840.

Garg, V., Aggarwal, S.P., Gupta, P.K., Nikam, B.R.,Thakur, P.K., Srivastav, S.K. and Senthil Kumar, A. 2017a. Assessment of Land Use Land Cover Change Impact on Hydrological Regime of a Basin. Environmental Earth Sciences, 76, DOI: https://doi.org/10.1007/s12665-017-6976-z

Garg, V., Aggarwal, S.P., Nikam, B.R. and Thakur, P.K. 2013. Hypothetical Scenario Based Impact Assessment of Climate Change on Runoff Potential of a Basin. ISH Journal of Hydraulic Engineering, 19(3), pp. 244-249.

Garg, V., Khwanchanok, A., Gupta, P.K., Aggarwal, S.P., Kiriwongwattana, K., Thakur, P.K. and Nikam, B.R. 2012. Urbanisation Effect on Hydrological Response: A Case Study of Asan River Watershed, India. Journal of Environment and Earth Science (IISTE), 2(9), pp. 39-50.

Garg, V., Senthil Kumar, A., Aggarwal, S.P., Kumar,V., Dhote, P.R., Thakur, P.K., Nikam, B.R., Sambare, R.S., Siddiqui, A., Muduli, P.R. and Rastogi, G. 2017b. Spectral Similarity Approach for Mapping Turbidity of an Inland Waterbody. Journal of Hydrology, 550, pp. 527-537.

Ghosh, S., Thakur, P.K., Sharma, R., Nandy, S., Garg, V., Amarnath, G., Bhattacharyya, S. 2017.The potential applications of satellite altimetry with SARAL/AltiKa for Indian inland waters. Proceedings of the National Academy of Sciences, India Section A: Physical Sciences, 87(4), pp. 661-677.

Nagesh Kumar D. and Reshmidevi T.V. 2013. Remote Sensing Applications in Water Resources. Journal of the Indian Institute of Science, 93:2.

Nikam, B.R., Garg, V., Jaya, K., Gupta, P.K., Srivastav, S.K., Thakur, P.K. and Aggarwal, S.P. 2018. Analyzing Future Water Availability and Hydrological Extremes in Krishna Basin under Changing Climatic Conditions. Arabian Journal of Geosciences, 10.1007/s12517-018-3936-1

Ritchie, J.C., Zimba, P.V., Everitt, J.H., 2003. Remote Sensing Techniques to Assess Water Quality. Photogramm. Eng. Remote Sens. 69,pp. 695-704.

Smith, L.C. (1997), Satellite remote sensing of river inundation area, stage, and discharge: a review. Hydrol. Process., 11, pp. 1427-1439.

1085(199708)11:10<1427::AID-HYP473>3.0.CO;2-S

Thakur, P. K., Aggarwal, S.P., Nikam, B. R., Garg, V., Chouksey, A. and Dhote P. R. 2018. Training, Education, Research and Capacity building needs and Future Requirements in applications of Geospatial Technology for Water Resources Management. Accepted in International Archives of the Photogrammetry, Remote Sensing and Spatial Information Sciences (ISPRS), ISPRS TCV MidTerm Symposium November 2018, India.

Thakur, P.K., Garg, V., Nikam, B.R., Chouksey, A., Aggarwal, S.P. and Dhote, P.R. 2017a. Cryospheric Studies in Indian Himalayan and Polar Region: Current Status, Advances and Future Prospects of Remote Sensing. Proceedings of the National Academy of Sciences, India Section A: Physical Sciences, 87(4), pp. 593-616.

Thakur, P.K., Ghosh, S., Garg, V., Aggarwal, S. P., Saha, S.K., Sharma, R. and Bhattacharyya, S. 2015. SARAL/AltiKa waveform analysis to monitor inland water levels: A case study of Maithon Reservoir, Jharkhand, India. Marine Geodesy, 38(Sup1), pp. 597-613. (Available Online, DOI:10.1080/01490419.2015.1039680)

Thakur, P.K., Nikam, B.R., Garg, V., Aggarwal, S.P., Chouksey, A., Dhote, P. and Ghosh, S. 2017b. Hydrological Parameters Estimation using Remote Sensing and GIS for Indian Region - A Review. Proc. Natl. Acad. Sci., India, Sect. A Physical Sciences, 87(4), pp. 641-659. https://doi.org/10.1007/s40010-017-0440-z.

Thakur, P.K., Bhardwaj, A., Thakur, A. 2008. Geospatial Technology Applications in Civil Engineering - A Review. In proceedings of HYDRO-2008, December 2008, MNIT, Jaipur, Rajasthan, India, pp. 120-133.

\section{Web-Links}

https://www.facilities.aicte-

india.org/dashboard/pages/dashboardaicte.php accessed on September 28, 2018.

https://www.facilities.aicteindia.org/dashboard/pages/angulardashboard.php\#!/approved accessed on September 28, 2018. 